\title{
Functional Recovery after Motor Cortical Stroke Related to Cerebellum Activity
}

\section{Rebeca Boltes Cecatto*}

São Paulo School of Medicine, University of São Paulo, Brazil

*Corresponding author: Rebeca Boltes Cecatto, University of São Paulo, Rua Caraibas 1336 apto 21 Perdizes, CEP 05020000 - São Paulo, Brazil, Tel: 55 (11) 38014568; Fax: 55 (11) 38648082; E-mail: rebeca.boltes@gmail.com

Received date: Nov 26, 2014, Accepted date: Dec 19, 2014, Published date: Dec 24, 2014

Copyright: ( 2014 Cecatto RB, et al. This is an open-access article distributed under the terms of the Creative Commons Attribution License, which permits unrestricted use, distribution, and reproduction in any medium, provided the original author and source are credited.

Keywords: Cerebellum; Rehabilitation; Stroke; Neuronal plasticity; cortex response to a motor training, than the cerebellum stimulation Motor cortex

\section{Commentary}

Although anatomical, experimental, functional and clinical studies suggest an important role of cerebellar pathways in motor cortical plasticity, little is known about the mechanisms through which the cerebellum exerts its influence on cerebral cortex. There are several reasons to investigate it [1].

Cerebellar circuitry is involved in the processing of sensory information by receiving ipsilaterally somatotopically organized somatosensory inputs [2]. Moreover, lesions of the cerebellum and its associated circuitry abolish or impair several types of motor learning [3].

Beside this in motor cortex stroke recovery, peripheral somatosensory stimulation was shown to provide improvements in impaired motor function4. It has been suggested that the organization of the motor cortex is greatly dependent on the balance between excitatory and inhibitory influences from sensory peripheral systems. Motor cortex excitability is affected by a number of pharmacological, electrophysiological and behavioral interventions. Longitudinal studies have shown that after a cortical injury, the improvement in motor activity is accompanied by an altered cortical activation pattern on transcranial magnetic stimulation (TMS) evaluation in motor-related regions such as the bilateral sensorimotor cortex, premotor cortex, cingulated motor areas and overall in cerebellum $[4,5]$.

In this way, experimental and human studies have evaluated the role of the cerebellum in motor skill learning after motor cortex stroke. Using TMS they have found that stimulation of the cerebellum could produce a clear change of the excitability of the contralateral sensory and motor cortex in health patients and also in neurological impaired ones. Recent studies also highlight that the cerebellum plays a key function in the adaptation of the motor cortex to repeated trains of peripheral sensory and motor training.

The hypothesis proposed is that the cerebellum could control cortical plastic changes by modulating cortical excitability in a discrete topographic manner and that this mechanism could induce the coupling between sensory inputs and motor outputs considered as the neurobiological substrate for recovery after motor cortex injury [6-10].

Several alternative possibilities are considered and ruled out. If the cerebellar-motorcortical connections could influence the motor recovery and learning after a motor cortical stroke, cerebellar stimulation therapies could interfere on the recovery of a task in motor cortex stroke patients and in the final results of neurorehabiltation therapies. Moreover if the cerebellum could modulate the motor could be added to conventional motor rehabilitation therapies for patients with motor cortex stroke.

In this way, the cerebelar stimulation like cerebellar transcranial direct current stimulation (tDCS) or especific pharmacotherapy that directly influences the pattern of cerebellum activation could be used like new rehabilitation strategies to promote functional recovery after motor cortex stroke $[11,12]$.

Future studies have to explore the neurophysiology of cerebellar afferent input to motor cortex to confirm such promising observations and optimize future rehabilitation therapies.

\section{References}

1. Molinari M, Filippini V, Leggio MG (2002) Neuronal plasticity of interrelated cerebellar and cortical networks. Neuroscience 111: 863-870.

2. Ito M (2006) Cerebellar circuitry as a neuronal machine. Prog Neurobiol 78: 272-303.

3. Attwell PJ, Cooke SF, Yeo CH (2002) Cerebellar function in consolidation of a motor memory. Neuron 34: 1011-1020.

4. Celnik PA, Cohen LG (2004) Modulation of motor function and cortical plasticity in health and disease. Restor Neurol Neurosci 22: 261-268.

5. Feydy A, Carlier R, Roby-Brami A, Bussel B, Cazalis F, et al. (2002) Longitudinal study of motor recovery after stroke: recruitment and focusing of brain activation. Stroke 33: 1610-1617.

6. Boyden ES, Katoh A, Raymond JL (2004) Cerebellum-dependent learning: the role of multiple plasticity mechanisms. Annu Rev Neurosci 27: 581-609.

7. Boyden ES, Katoh A, Pyle JL, Chatila TA, Tsien RW, et al. (2006) Selective engagement of plasticity mechanisms for motor memory storage. Neuron 51: 823-834.

8. Buitrago MM, Luft AR, Thakor NV, Blue ME, Hanley DF (2004) Effects of somatosensory electrical stimulation on neuronal injury after global hypoxia-ischemia. Exp Brain Res 158: 336-344.

9. Kaelin-Lang A, Luft AR, Sawaki L, Burstein AH, Sohn YH, et al. (2002) Modulation of human corticomotor excitability by somatosensory input. J Physiol 540: 623-633.

10. Luft AR, Kaelin-Lang A, Hauser TK, Buitrago MM, Thakor NV, et al. (2002) Modulation of rodent cortical motor excitability by somatosensory input. Exp Brain Res 142: 562-569.

11. 11. Grimaldi G, Argyropoulos GP, Bastian A, Cortes M, Davis NJ, Edwards DJ, Ferrucci R, Fregni F, Galea JM, Hamada M, Manto M, Miall RC, Morales-Quezada L, Pope PA, Priori A, Rothwell J, Tomlinson SP, Celnik P. Cerebellar Transcranial Direct Current Stimulation (ctDCS): A Novel Approach to Understanding Cerebellar Function in Health and Disease. Neuroscientist 2014

12. Grimaldi G, Argyropoulos GP, Boehringer A, Celnik P, Edwards MJ, et al. (2014) Non-invasive cerebellar stimulation--a consensus paper. Cerebellum 13: 121-138. 